\title{
Herpes simplex virus induces the marked up- regulation of the zinc finger transcriptional factor INSM1, which modulates the expression and localization of the immediate early protein ICPO
}

\author{
Maki Kamakura, Fumi Goshima, Chenhong Luo, Hiroshi Kimura and Yukihiro Nishiyama*
}

\begin{abstract}
Background: Herpes simplex viruses (HSVs) rapidly shut off macromolecular synthesis in host cells. In contrast, global microarray analyses have shown that HSV infection markedly up-regulates a number of host cell genes that may play important roles in HSV-host cell interactions. To understand the regulatory mechanisms involved, we initiated studies focusing on the zinc finger transcription factor insulinoma-associated 1 (INSM1), a host cell protein markedly up-regulated by HSV infection.
\end{abstract}

Results: INSM1 gene expression in HSV-1-infected normal human epidermal keratinocytes increased at least 400fold $9 \mathrm{~h}$ after infection; INSM1 promoter activity was also markedly stimulated. Expression and subcellular localization of the immediate early HSV protein ICPO was affected by INSM1 expression, and chromatin immunoprecipitation (ChIP) assays revealed binding of INSM1 to the ICPO promoter. Moreover, the role of INSM1 in HSV-1 infection was further clarified by inhibition of HSV-1 replication by INSM1-specific siRNA.

Conclusions: The results suggest that INSM1 up-regulation plays a positive role in HSV-1 replication, probably by binding to the ICPO promoter.

\section{Background}

Herpes simplex virus types 1 (HSV-1) and 2 (HSV-2) are large DNA viruses with genomes consisting of at least 74 genes [1], which are classified into four groups with respect to their order of expression on the entry of HSV into the host cell. Immediate early (IE) genes are transcribed without prior viral protein synthesis. Early genes are expressed before the onset of viral DNA synthesis and require IE gene expression. Expression of delayed early genes is partially dependent on viral DNA synthesis, but that of late or true late genes is completely dependent on viral DNA synthesis. The cascade of HSV gene expression is tightly regulated by viral and cellular factors [2-6].

HSV infection markedly affects expression of host cell genes. The HSV genome encodes a virion-associated

\footnotetext{
*Correspondence: ynishiya@med.nagoya-u.ac.jp

Department of Virology, Nagoya Graduate School of Medicine, 65 Tsurumaicho, Showa-ku, Nagoya 466-8550, Japan
}

endonuclease UL41 that degrades viral and cellular mRNA early in infection. The IE protein ICP27 also inhibits cellular gene expression by blocking mRNA splicing [7]. Although the high level of viral transcription appears to overcome the effect of these proteins, host cell protein synthesis is strongly suppressed early in HSV infection. However, microarray analysis has shown that HSV-infected cells express high levels of a significant number of cellular genes [8]. We have shown that transcript levels of the cellular genes ZSCAN4, ZNF342, and HBA2 increased by more than 100-fold in both HSV-1- and HSV-2-infected HEp-2 cells [8]. Although whether enhanced expression of these three genes at the transcriptional level corresponds to increased expression of their gene products is unclear, such marked host cell responses may reveal novel regulatory mechanisms involved in HSV replication.

Cells of the developing central and peripheral nervous system as well as endocrine cells of the developing pancreas and intestine express insulinoma-associated 1 
(INSM1), a zinc finger transcription factor [9]. More specifically, INSM1 gene expression is highly restricted to fetal pancreatic and brain tissues [10-14]. Since INSM1 is also highly expressed in tumors of neuroendocrine origin, its promoter could serve as a tumor-specific target for gene therapy for neuroendocrine tumors [15-17]. Recent studies have shown that INSM1 is a crucial component of the transcriptional network that controls differentiation of the sympatho-adrenal lineage [18], and that INSM1 is involved in the generation and expansion of basal progenitors in the developing neocortex [19].

In the present study, we found that INSM1 gene expression was markedly stimulated by HSV-1 and HSV-2 infections of normal human epidermal keratinocytes (NHEK) and HaCaT cells. We also report the effects of INSM1 on expression and distribution of the IE protein ICP0 and a possible role of INSM1 in HSV-1 replication.

\section{Results}

Microarray analysis of cellular transcriptional responses to HSV-1 and HSV-2 infections

We previously reported that HSV-1 and HSV-2 infections markedly increased mRNA levels of specific cellular genes in HEp-2 cells [8]. Since the HEp-2 cell line is derived from a tumor, responses of HEp-2 cells to HSV infections may differ from those of non-transformed cells. Therefore, we performed global microarray analysis of NHEK cells that were mock infected or infected with wild-type (WT) HSV-1, WT HSV-2, and their US3 mutants. While US3 is not essential for viral replication in vitro, the protein kinases encoded by the US3 genes of HSV-1 and HSV-2 have been shown to play important roles in various aspects of viral replication and pathogenicity, including regulation of apoptosis and signal transduction and virion maturation [20-24]. We thus examined the transcriptional responses of cells infected with the US3 mutants. Table 1 shows cellular genes whose mRNA levels increased by at least 4 -fold $9 \mathrm{~h}$ after infection. Among the 54,765 probe sets examined, levels of 189 transcripts increased by at least 4-fold in infected NHEK cells and those of 108 transcripts increased in common in both NHEK and HEp-2 cells. In NHEK cells, INSM1 expression was always highly upregulated in all cases. Our microarray analysis showed that the level of INSM1 mRNAs increased by at least 400-fold $9 \mathrm{~h}$ after infection in HSV-infected cells compared with mock-infected cells. Although the extent of increase was higher in US3 mutant-infected cells than in WT-infected cells, the mechanism remains unclear. The marked up-regulation of INSM1 by HSV infections was confirmed by reverse transcription (RT)-PCR analysis of NHEK, $\mathrm{HaCaT}$, and HEp-2 cells (Figure 1). Moreover, we found that such up-regulation was not induced by UV-inactivated HSV-1 (Figure 1B). The INSM1 gene, similar to most HSV genes, lacks introns [25]. INSM1 has recently been shown to bind cyclin D1 and play an important role in switching cells between cellular proliferation and differentiation pathways [26]. Therefore, we focused here on HSV-induced INSM1 up-regulation.

\section{HSV infection stimulates human INSM1 promoter activity}

To investigate the effect of HSV infection on INSM1 promoter-dependent expression, reporter gene assays were performed. Figure $2 \mathrm{~A}$ shows a schematic representation of human INSM1 promoter region $(-441$ to +26 bp), which was amplified by PCR using DNA extracted from HEp-2 cells, confirmed by sequence analysis, and cloned into the pGL3 luciferase reporter vector. $\mathrm{HaCaT}$ and $\mathrm{HEp}-2$ cells were transfected with this construct or empty vector DNA and then infected with WT HSV-1 at a multiplicity of infection (MOI) of 3 plaque-forming units (PFU)/cell $24 \mathrm{~h}$ after transfection. The cells were collected $9 \mathrm{~h}$ after infection. INSM1 promoter activity increased approximately 350fold in infected $\mathrm{HaCaT}$ cells (Figure 2B) and 80-fold in infected HEp-2 cells (Figure 2C). In infected HEp-2 and $\mathrm{HaCaT}$ cells, luciferase activity rapidly increased until $12 \mathrm{~h}$ after infection (data not shown). Extracts prepared from cells infected with UV-inactivated HSV1 failed to support INSM1 promoter activity. These observations indicate that HSV infection activates the INSM1 promoter.

\section{Subcellular localization of human full-length INSM1 (INSM1-FL) and mutant proteins}

We next constructed human INSM1 expression vectors to investigate the effects of INSM1 on HSV replication. Human INSM1 is a $58-\mathrm{kDa}$ protein that contains five zinc finger motifs in its $\mathrm{C}$-terminal domain (Figure 3A). The $\mathrm{N}$-terminal domain contains a putative nuclear localization signal (NLS) and proline-rich domains that interact with cyclin D1 [26]. Thus, the expression vectors of INSM1 $\mathrm{N}$ - and C-terminal domains were constructed and used along with a INSM1-FL construct to transfect HEp-2 cells. The cells were subjected to Western blot analysis $24 \mathrm{~h}$ after transfection. As determined by Western blot analysis, the anti-INSM1 antibody raised against the human INSM1 C-terminal peptides (NP_002187, amino acid residues 393-442) reacted weakly with a $60-\mathrm{kDa}$ band in INSM1-FL-transfected cells and a 40-kDa band in INSM1-C-transfected cells (Figure 3B). Both bands were easily detected by the antiMyc antibody because of the Myc-tag epitope expressed by the constructs. Although a $50-\mathrm{kDa}$ band was detected in all cases, it appeared to be non-specific because the apparent molecular size was smaller than the expected 
Table 1 Human genes induced by HSV infection of NHEK cells at $9 \mathrm{~h}$ after infection

\begin{tabular}{|c|c|c|c|c|c|c|c|}
\hline \multirow{3}{*}{$\begin{array}{l}\text { Representative } \\
\text { Public ID }{ }^{\mathrm{a}}\end{array}$} & \multirow{3}{*}{$\begin{array}{c}\text { Gene } \\
\text { Symbol }\end{array}$} & \multirow[t]{3}{*}{ Gene Title } & \multicolumn{4}{|c|}{ Fold change $^{b}$} & \multirow{3}{*}{$\begin{array}{l}\text { Gene Ontology } \\
\text { Biological Process }\end{array}$} \\
\hline & & & \multicolumn{2}{|c|}{ HSV-1 } & \multicolumn{2}{|c|}{ HSV-2 } & \\
\hline & & & WT & $\Delta$ US3 & WT & $\Delta$ US3 & \\
\hline NM_005083 & U2AF1L1 & U2 small nuclear RNA auxillary factor 1-like 1 & 4.0 & 13.0 & 5.3 & 7.5 & - \\
\hline AV712346 & REEP5 & Receptor accessory protein 5 & 9.8 & 11.3 & 11.3 & 9.8 & - \\
\hline AK091308 & NARG1 & NMDA receptor regulated 1 & 26.0 & 59.7 & 36.8 & 19.7 & - \\
\hline AW613101 & KCNQ10T1 & KCNQ1 overlapping transcript 1 & 32.0 & 45.3 & 42.2 & 78.8 & - \\
\hline AW014728 & FLJ39575 & hypothetical protein FLJ39575 & 90.5 & 111.4 & 78.8 & 207.9 & - \\
\hline AL359567 & IGSF4 & Immunoglobulin superfamily, member 4 & 8.0 & 17.1 & 10.6 & 7.5 & immune response \\
\hline NM_000594 & $T N F$ & $\begin{array}{l}\text { tumor necrosis factor (TNF superfamily, member } \\
\text { 2) }\end{array}$ & 21.1 & 34.3 & 8.6 & 11.3 & immune response \\
\hline AW135003 & API5 & Apoptosis inhibitor 5 & 4.3 & 6.1 & 4.6 & 5.7 & apoptosis \\
\hline AW511239 & RHOT1 & Ras homolog gene family, member $\mathrm{T} 1$ & 4.9 & 6.1 & 6.5 & 8.6 & apoptosis \\
\hline AA005430 & CROP & $\begin{array}{c}\text { Cisplatin resistance-associated overexpressed } \\
\text { protein }\end{array}$ & 7.0 & 13.0 & 13.0 & 9.8 & apoptosis \\
\hline NM_006538 & $B C L 2 L 11$ & BCL2-like 11 (apoptosis facilitator) & 39.4 & 29.9 & 19.7 & 39.4 & apoptosis \\
\hline NM_006910 & RBBP6 & retinoblastoma binding protein 6 & 4.0 & 6.5 & 6.1 & 6.1 & cell cycle \\
\hline NM_000076 & CDKN1C & cyclin-dependent kinase inhibitor 1C (p57, Kip2) & 4.9 & 5.7 & 8.0 & 7.0 & cell cycle \\
\hline X07868 & IGF2 & insulin-like growth factor 2 (somatomedin A) & 6.1 & 7.0 & 5.7 & 7.5 & cell cycle \\
\hline NM_015675 & GADD45B & growth arrest and DNA-damage-inducible, beta & 12.1 & 14.9 & 14.9 & 34.3 & cell cycle \\
\hline NM_003914 & CCNA1 & cyclin A1 & 13.0 & 21.1 & 13.0 & 14.9 & cell cycle \\
\hline BE348555 & PDZK1 & PDZ domain containing 1 & 4.0 & 9.2 & 4.6 & 6.5 & signal transduction \\
\hline NM_005204 & МАРЗК8 & mitogen-activated protein kinase kinase kinase 8 & 4.0 & 12.1 & 4.6 & 6.5 & signal transduction \\
\hline NM_003328 & TXK & TXK tyrosine kinase & 5.7 & 5.3 & 9.8 & 10.6 & signal transduction \\
\hline NM_014823 & WNK1 & WNK lysine deficient protein kinase 1 & 6.1 & 5.3 & 9.8 & 7.0 & signal transduction \\
\hline Al684439 & GRAP & GRB2-related adaptor protein & 13.9 & 8.6 & 6.1 & 16.0 & signal transduction \\
\hline NM_018390 & PLCXD1 & $\begin{array}{c}\text { phosphatidylinositol-specific phospholipase } \mathrm{C}, \mathrm{X} \\
\text { domain containing } 1\end{array}$ & 11.3 & 34.3 & 17.1 & 19.7 & signal transduction \\
\hline AF069506 & RASD1 & RAS, dexamethasone-induced 1 & 111.4 & 104.0 & 111.4 & 207.9 & signal transduction \\
\hline NM_004692 & INA & $\begin{array}{l}\text { internexin neuronal intermediate filament protein, } \\
\text { alpha }\end{array}$ & 6.5 & 9.8 & 4.6 & 4.6 & $\begin{array}{l}\text { cell adhesion and } \\
\text { cytoskeleton }\end{array}$ \\
\hline Al668588 & SPTAN1 & Spectrin, alpha, non-erythrocytic 1 (alpha-fodrin) & 16.0 & 27.9 & 26.0 & 26.0 & $\begin{array}{l}\text { cell adhesion and } \\
\text { cyctoskeleton }\end{array}$ \\
\hline NM_005382 & NEFM & neurofilament, medium polypeptide $150 \mathrm{kDa}$ & 29.9 & 36.8 & 26.0 & 55.7 & $\begin{array}{l}\text { cell adhesion and } \\
\text { cytoskeleton }\end{array}$ \\
\hline U26662 & NPTX2 & neuronal pentraxin II & 45.3 & 52.0 & 32.0 & 34.3 & cell communication \\
\hline NM_002105 & $H 2 A F X$ & $\mathrm{H} 2 \mathrm{~A}$ histone family, member $\mathrm{X}$ & 10.6 & 13.9 & 7.5 & 13.0 & DNA / chromosome \\
\hline NM_003655 & CBX4 & $\begin{array}{c}\text { chromobox homolog } 4 \text { (Pc class homolog, } \\
\text { Drosophila) }\end{array}$ & 24.3 & 29.9 & 14.9 & 36.8 & DNA/chromosome \\
\hline AL832081 & ZNF131 & Zinc finger protein 131 & 4.3 & 7.0 & 6.1 & 9.8 & transcription \\
\hline T79183 & $J A Z F 1$ & JAZF zinc finger 1 & 5.7 & 4.9 & 7.5 & 8.6 & transcription \\
\hline D42040 & BRD2 & bromodomain containing 2 & 6.1 & 9.2 & 6.1 & 8.6 & transcription \\
\hline NM_001452 & FOXF2 & forkhead box F2 & 6.5 & 14.9 & 11.3 & 16.0 & transcription \\
\hline NM_005904 & SMAD7 & SMAD family member 7 & 7.0 & 9.8 & 7.0 & 12.1 & transcription \\
\hline AF193855 & $Z I C 2$ & $\begin{array}{c}\text { Zic family member } 2 \text { (odd-paired homolog, } \\
\text { Drosophila) }\end{array}$ & 13.0 & 55.7 & 34.3 & 68.6 & transcription \\
\hline NM_001674 & ATF3 & activating transcription factor 3 & 13.9 & 16.0 & 36.8 & 26.0 & transcription \\
\hline Al459175 & KLF3 & Kruppel-like factor 3 (basic) & 14.9 & 18.4 & 16.0 & 14.9 & transcription \\
\hline NM_004405 & $D L X 2$ & distal-less homeobox 2 & 17.1 & 24.3 & 13.9 & 42.2 & transcription \\
\hline AW274658 & ING1 & Inhibitor of growth family, member 1 & 19.7 & 12.1 & 10.6 & 24.3 & transcription \\
\hline NM_002166 & ID2 & $\begin{array}{c}\text { inhibitor of DNA binding 2, dominant negative } \\
\text { helix-loop-helix protein }\end{array}$ & 24.3 & 22.6 & 19.7 & 42.2 & transcription \\
\hline NM_002448 & MSX1 & msh homeobox 1 & 59.7 & 84.4 & 48.5 & 128.0 & transcription \\
\hline NM_152677 & ZSCAN4 & zinc finger and SCAN domain containing 4 & 97.0 & 362.0 & 55.7 & 147.0 & transcription \\
\hline
\end{tabular}


Table 1 Human genes induced by HSV infection of NHEK cells at $\mathbf{9 h}$ after infection (Continued)

\begin{tabular}{|c|c|c|c|c|c|c|c|}
\hline AA761573 & ZNF342 & zinc finger protein 342 & 128.0 & 256.0 & 111.4 & 294.1 & transcription \\
\hline NM_002196 & INSM1 & insulinoma-associated 1 & 445.7 & 776.0 & 955.4 & 1782.9 & transcription \\
\hline Al906424 & HNRPM & Heterogeneous nuclear ribonucleoprotein $M$ & 4.3 & 5.7 & 6.5 & 11.3 & RNA / translation \\
\hline Al445255 & SFRS3 & Splicing factor, arginine/serine-rich 3 & 13.0 & 14.9 & 14.9 & 21.1 & RNA / translation \\
\hline R17062 & PABPC1 & Poly(A) binding protein, cytoplasmic 1 & 32.0 & 39.4 & 48.5 & 90.5 & RNA / translation \\
\hline BF195994 & PIAS2 & Protein inhibitor of activated STAT, 2 & 4.3 & 5.7 & 4.6 & 9.2 & $\begin{array}{l}\text { protein folding and } \\
\text { modification }\end{array}$ \\
\hline U56725 & HSPA2 & heat shock 70kDa protein 2 & 5.7 & 8.6 & 4.0 & 5.7 & $\begin{array}{l}\text { protein folding and } \\
\text { modification }\end{array}$ \\
\hline AU158573 & ABHD5 & Abhydrolase domain containing 5 & 13.0 & 18.4 & 11.3 & 19.7 & $\begin{array}{l}\text { protein folding and } \\
\text { modification }\end{array}$ \\
\hline NM_000104 & CYP1B1 & $\begin{array}{c}\text { cytochrome P450, family } 1 \text {, subfamily B, } \\
\text { polypeptide } 1\end{array}$ & 6.1 & 6.5 & 13.0 & 18.4 & development \\
\hline NM_001529 & HHEX & homeobox, hematopoietically expressed & 17.1 & 48.5 & 97.0 & 68.6 & development \\
\hline NM_002405 & MFNG & $\begin{array}{l}\text { MFNG O-fucosylpeptide 3-beta-N- } \\
\text { acetylglucosaminyltransferase }\end{array}$ & 4.0 & 8.0 & 4.6 & 8.6 & developmental process \\
\hline NM_000361 & $T H B D$ & thrombomodulin & 9.8 & 11.3 & 5.7 & 8.6 & biological regulation \\
\hline NM_000499 & CYP1A1 & $\begin{array}{c}\text { cytochrome P450, family } 1 \text {, subfamily A, } \\
\text { polypeptide } 1\end{array}$ & 4.3 & 4.9 & 5.3 & 7.5 & cellular metabolism \\
\hline A1625747 & ADRB1 & adrenergic, beta-1-, receptor & 6.1 & 18.4 & 7.5 & 10.6 & cellular metabolism \\
\hline NM_003895 & SYNJ1 & synaptojanin 1 & 6.5 & 13.0 & 7.5 & 11.3 & cellular metabolism \\
\hline NM_000558 & HBA1 & hemoglobin, alpha 1 & 55.7 & 84.4 & 34.3 & 137.2 & transport \\
\hline
\end{tabular}

${ }^{a}$ GeneBank accession No. corresponds to sequence to which the Affymetrix U133 plus 2 probe set was designed.

${ }^{\mathrm{b}}$ Fold change was calculated by comparison to values obtained from the mock-infected cells.

size of human INSM1-FL and the band intensity did not change after HSV infections.

Transfected cells were fixed, reacted with anti-human INSM1 and anti-Myc antibodies, and examined by confocal laser microscopy (Figure 3C). In INSM1-FL-transfected cells, specific INSM1 fluorescence was detected exclusively in the nucleus. In INSM1-N-transfected cells, no specific fluorescence was detected when examined with the anti-INSM1 antibody. However, immunofluorescence staining using the anti-Myc antibody revealed that INSM1-N was localized in the nucleus in a majority of cells and in the cytoplasm of some cells. In contrast, INSM1-C that lacked a putative NLS predominantly localized in the cytoplasm, as expected.

Effect of INSM1 and its mutant proteins on expression and subcellular localization of ICPO

INSM1-binding sequences have been identified as $\mathrm{T}^{\mathrm{G}}$ / $\mathrm{T}^{\mathrm{C}} / \mathrm{T}^{\mathrm{C}} / \mathrm{T}^{\mathrm{T}} / \mathrm{AGGGG}^{\mathrm{G}} / \mathrm{TC}^{\mathrm{G}} / \mathrm{A}$ [27]. To identify consensus sequences for INSM1 binding in HSV-1 $\left(17^{+}\right.$, X14112) and HSV-2 (HG52, Z86099) genomes, their complete genomic sequences were analyzed using GENETYX version 8 (Software Development Co., Tokyo, Japan). The results showed that both HSV-1 and HSV-2 genomes contain several INSM1-binding sequences, but only one sequence was present in the upstream promoter region of the specific gene ICP0, suggesting that ICP0 could be an INSM1 target. Therefore, we examined the effect of INSM1 on expression and localization of ICP0 in HSV-1-infected cells. The cells were transfected with each INSM1 expression vector and infected with HSV-1 at MOI of $3 \mathrm{PFU} /$ cell $24 \mathrm{~h}$ after transfection. The cells were then fixed at appropriate times after infection and processed for visualization by immunofluorescent confocal laser microscopy (Figure 4). ICP0 signals were detected as dots in the nucleus $4 \mathrm{~h}$ after infection in empty vectortransfected cells, as expected (Figure 4A). The distribution pattern of ICP0 in INSM1-FL-expressing cells was similar to that in mock-transfected cells, but the intensity of ICP0-specific fluorescence appeared to be higher in INSM1-FL-expressing cells than in nonexpressing cells. Such augmented expression of ICP0 in INSM1-FL-expressing cells was more clearly observed in Vero and $\mathrm{HaCaT}$ cells (Figure 4B and 4C). Interestingly, ICP0 expression was strongly suppressed in most INSM1-N-expressing cells in contrast to INSM1-C-expressing cells (Figure 4A). Nuclear ICP0 is known to translocate to the cytoplasm late in HSV infection [28]. In fact, ICP0 was predominantly localizaed in the cytoplasm of mock-transfected cells $18 \mathrm{~h}$ after infection (Figure 4D). In INSM1-FL-expressing cells, however, ICP0 remained in the nucleus, indicating that INSM1 can inhibit the translocation of ICP0 to the cytoplasm late in infection.

We also examined the effect of INSM1 on expression and subcellular localization of the single-strand DNAbinding protein ICP8 (Figure 5). No evidence showed 


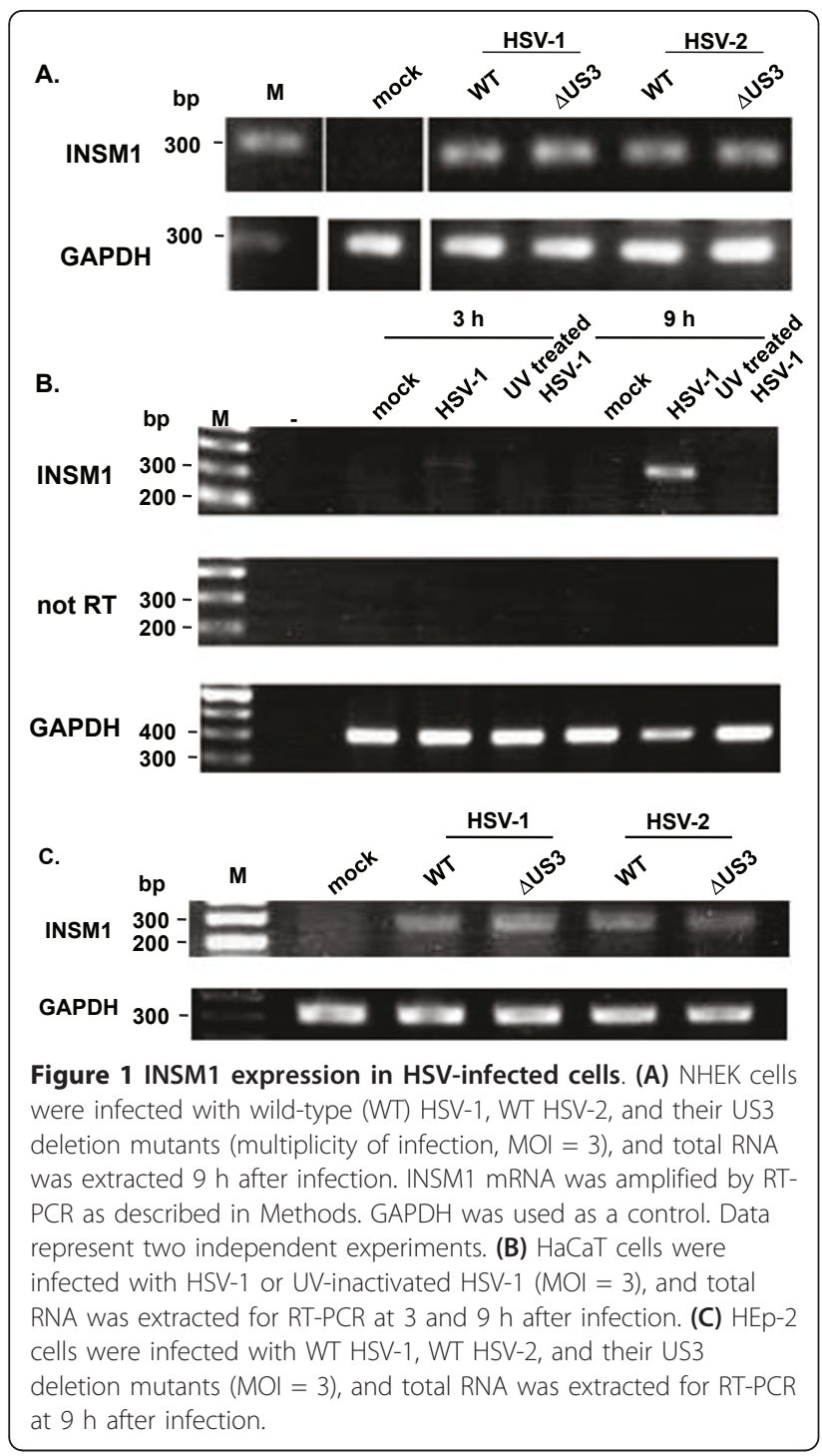

that INSM1-FL or INSM1-C expression affected ICP8 expression, but ICP8 expression appeared to be suppressed in INSM1-N-expressing cells. In HSV-1-infected cells, INSM1-FL localized to the replication compartment late in infection. Furthermore, subcellular localization of INSM1-N and INSM1-C was found to be affected by HSV-1 infection, with both mutant proteins co-localizing with ICP8 in the nucleus.

These observations suggest that INSM1 expression enhanced ICP0 expression early in infection but inhibited the translocation of ICPO to the cytoplasm late in infection, and that ICPO expression was suppressed by INSM1-N even during the late phase. However, we have so far failed to show a significant difference in ICP0 expression between INSM1-transfected or mock-transfected cells by Western blot analysis, probably because of low transfection efficiency.
A.

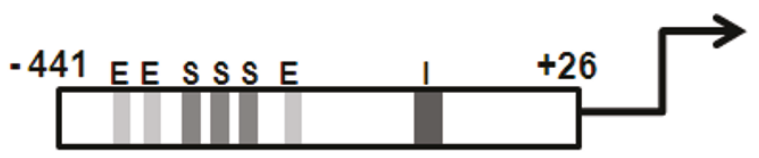

B.

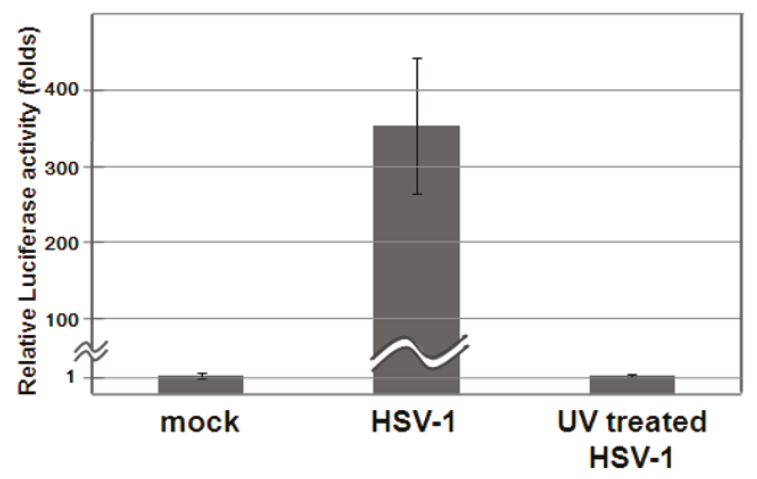

C.

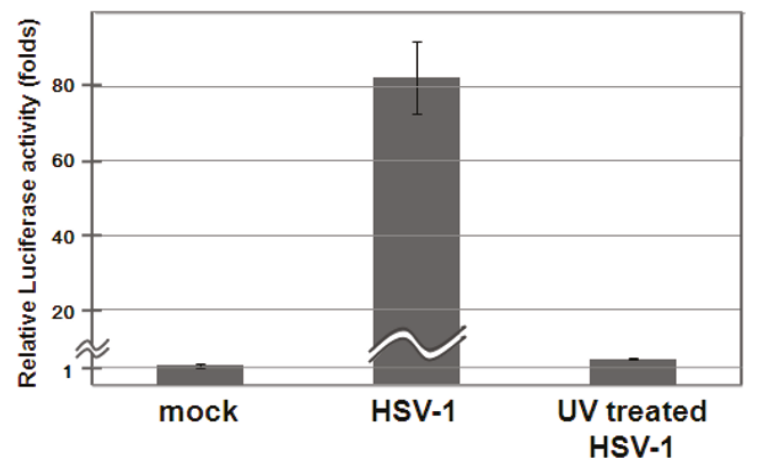

Figure 2 Effect of HSV infection on INSM1 promoter-directed luciferase activities. (A) Schematic representation of the INSM1 promoter region from position -441 to +26 . Predicted transcription factor binding sites are as follows: E (E box, 5'-CATTT-3', 5'CACGTG-3', and 5'-CATCTG-3'), S (SP1-binding site, 5'GGGGCCGGGC-3' and 5'-CGGGCGGGC-3'), and I (INSM1-binding site, 5'-CTCCAGGGGAAGC-3'). (B and C) Luciferase reporter assays. HaCaT (B) and HEp-2 (C) cells were infected with WT HSV-1 and UVinactivated HSV-1 $(\mathrm{MOI}=3)$ and harvested $9 \mathrm{~h}$ after infection. Luciferase activity was measured as described in Methods. The results are shown as means \pm standard deviation (SD).

\section{Effect of INSM1 on ICPO promoter activity}

As described above, the ICP0 promoter contains the INSM1-binding consensus sequence $\mathrm{T}^{\mathrm{G}} / \mathrm{T}^{\mathrm{C}} / \mathrm{T}^{\mathrm{C}} / \mathrm{T}^{\mathrm{T}} /$ $\mathrm{AGGGG}^{\mathrm{G}} / \mathrm{TC}^{\mathrm{G}} / \mathrm{A}$ [27] and several potential INSM1binding sequences, TNNNNGGGGNCN (Figure 6A). In addition, our observations showed that INSM1 expression significantly modulated ICP0 expression in HSV-1infected cells. Therefore, we wanted to determine the effect of INSM1 on the ICP0 promoter by luciferase reporter gene assays. Because the ICP0 promoter 


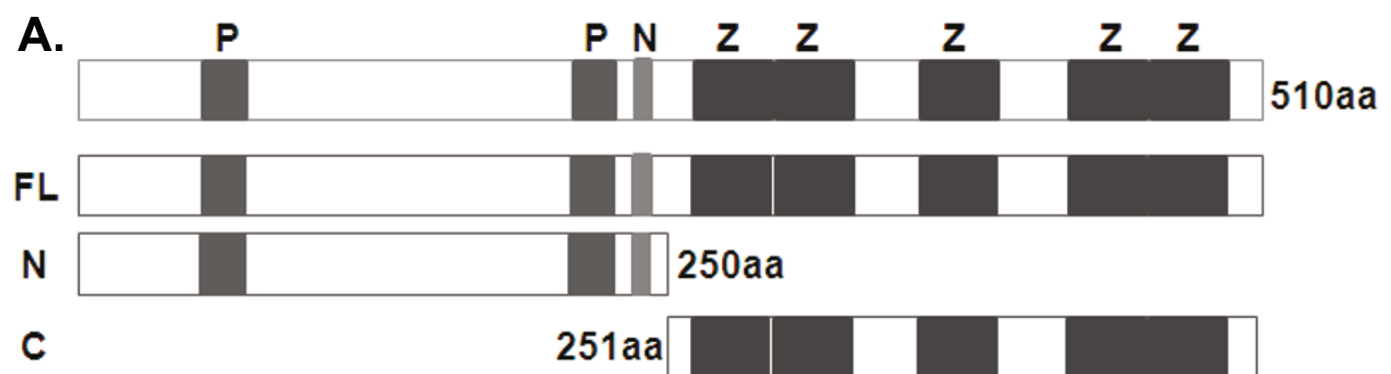

B. WB

INSM1 Myc

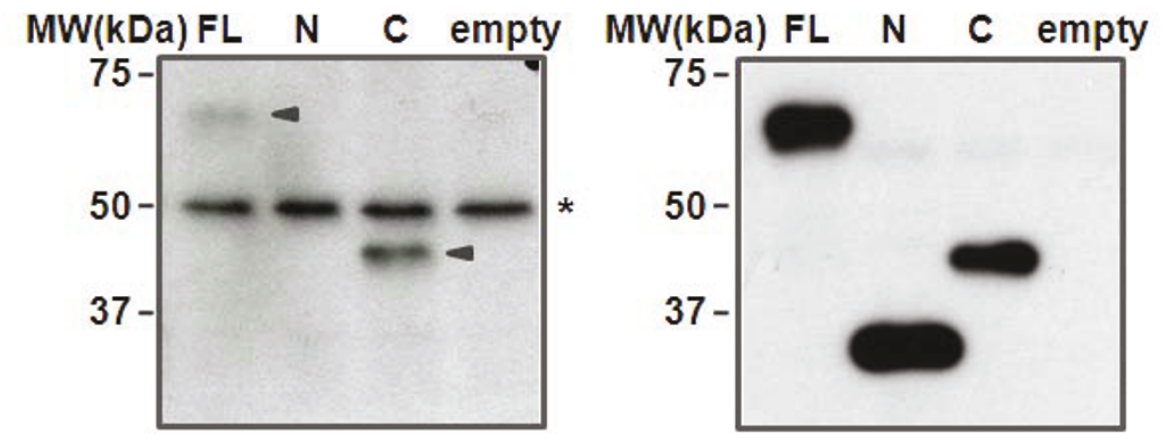

C.

INSM1

Myc

merge

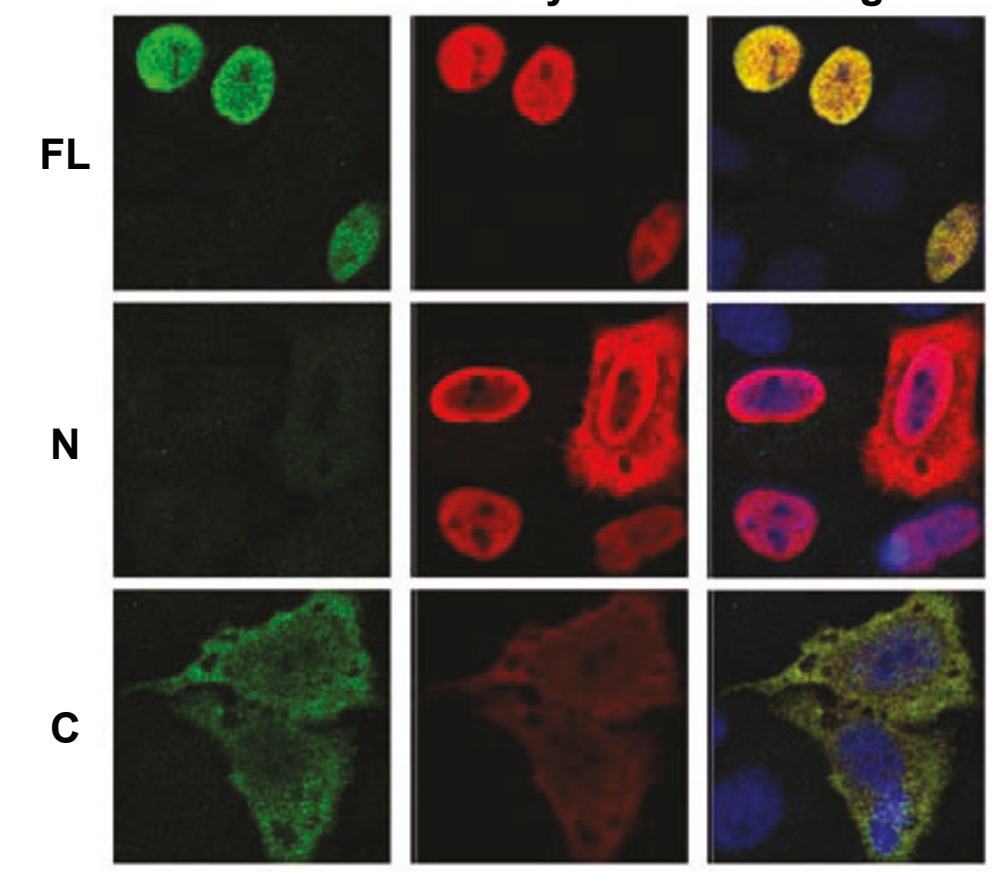

Figure 3 Expression of INSM1 and INSM1 deletion mutants. (A) Schematic diagram of INSM1 domain structure. INSM1 has two proline-rich domains ( $\mathrm{P}$, amino acid residues 43-58 and 75-84), one NLS (N, amino acids residues 221-246) and five C2H2 zinc finger motifs (Z). HEp-2 cells were transfected with FL or deletion mutant INSM1 expression vectors and incubated for 24-48 $\mathrm{h}$ prior to analysis by Western blotting (B) and confocal microscopy (C). The positions of mutant proteins detected by polyclonal antibodies are shown. Anti-Myc rabbit polyclonal antibody (B, right) and anti-INSM1 rabbit polyclonal antibody (B, left) were used to detect full-length and mutant proteins, respectively. The asterisk indicates a non-specific band. 


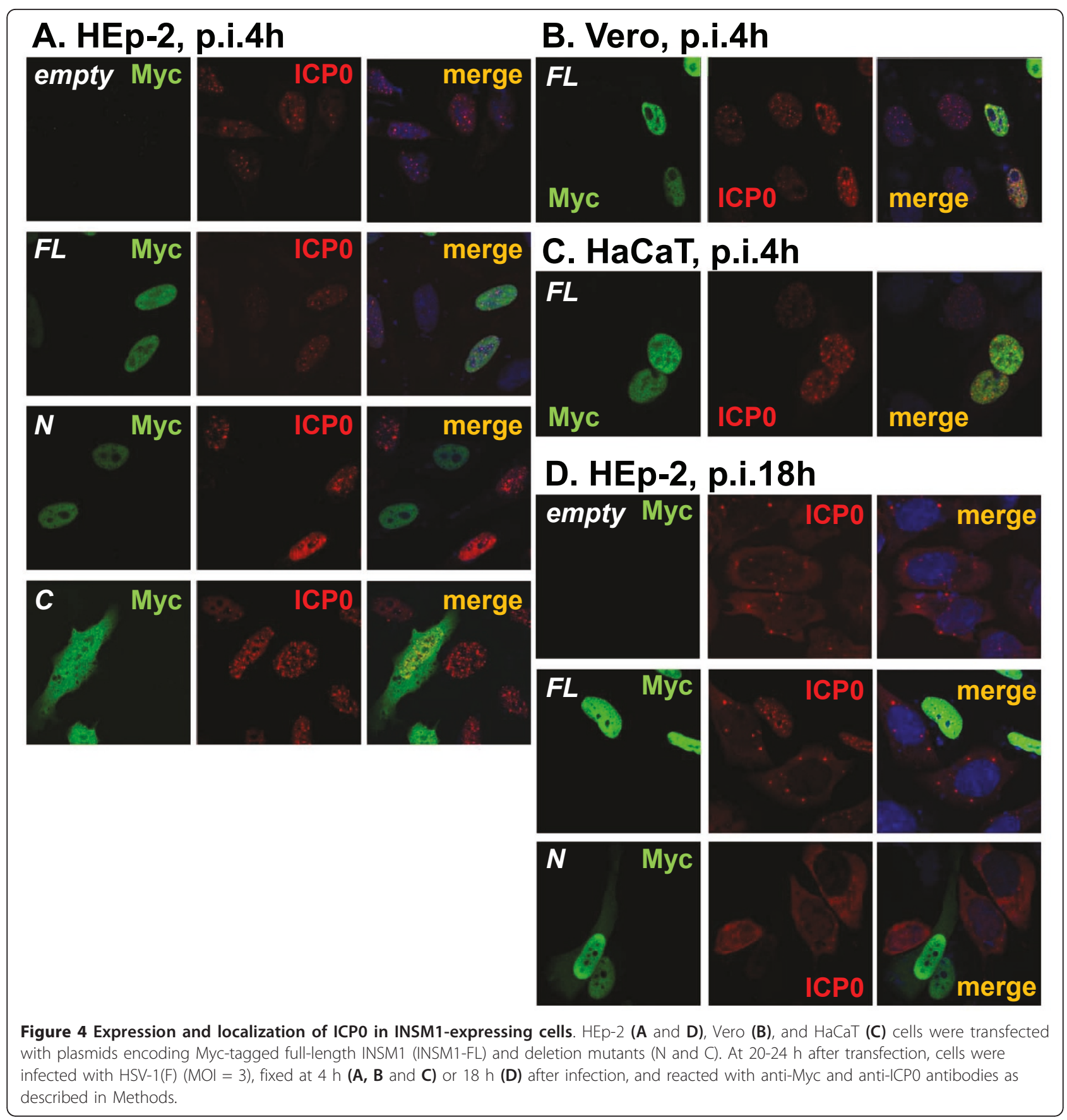

contains binding sites for the Oct-1 protein complex containing host cell factor (HCF), and the HSV virionassociated transactivator VP16 $[29,30]$ and the transcription of the ICP0 gene is highly activated by VP16 [31], we examined the effect of INSM1 on ICP0 promoter activity in the presence of VP16. In fact, the ICP0 promoter exhibited extremely weak activity in the absence of VP16 when examined by reporter assays in HEp-2 cells (data not shown); therefore, the effect of INSM1 was measured under conditions in which cells were co- transfected with a VP16 expression vector (Figure 6B). Luciferase activity was enhanced approximately 20-fold by the VP16 expression vector and was further augmented by INSM1 expression although the addition of an empty vector also increased the luciferase activity to some extent. The difference between the INSM1 expression vector and empty vector was statistically significant and repeatedly observed in three independent experiments. However, the addition of increased amounts of the INSM1 expression vector suppressed luciferase 


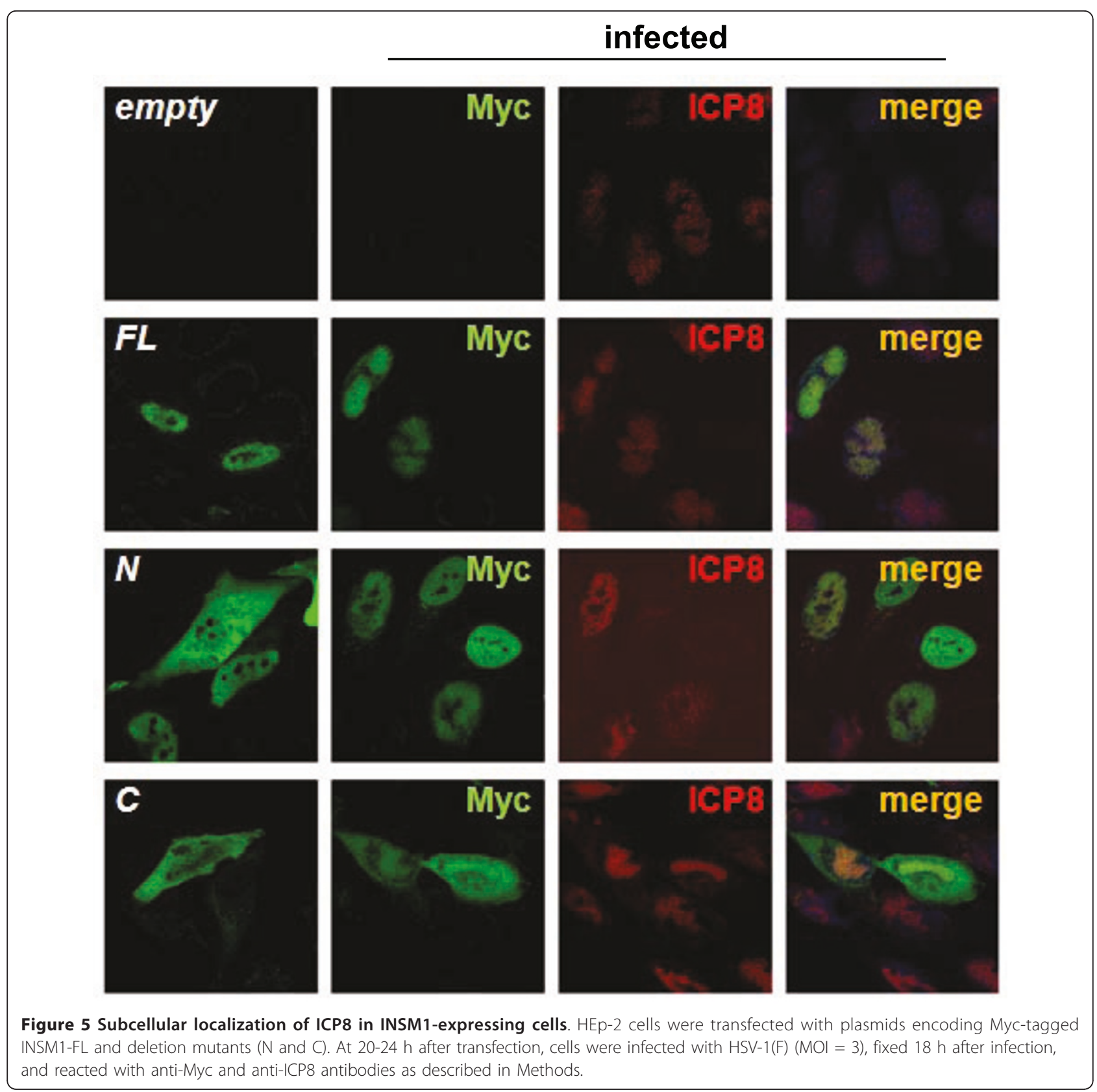

expression. A similar trend was observed in HEp-2 and $\mathrm{HaCaT}$ cells. These results indicate that the ICP0 promoter can be activated by INSM1 under specific conditions.

\section{INSM1 binds the ICP0 promoter}

We performed ChIP assays to determine whether INSM1 binds the ICP0 promoter. Thus, HEp-2 cells were transfected with empty and INSM1-FL vectors, infected with HSV-1(F) $48 \mathrm{~h}$ after transfection, fixed with formaldehyde $7 \mathrm{~h}$ after infection, and processed for
ChIP assays (see Methods). Chromatin solution was incubated with the anti-Myc antibody or control IgG, and the immunoprecipitated complexes were analyzed by PCR using ICP0 promoter-specific primers and ICP27 promoter-specific primers as controls. Figure 7 shows that ICP0 promoter sequences were amplified by chromatin complexes precipitated by anti-Myc antibodies, but not by normal IgG. The ICP27 promoter sequence was not detectably amplified in either case. Therefore, these results indicate that INSM1 selectively binds the ICP0 promoter. 
A.

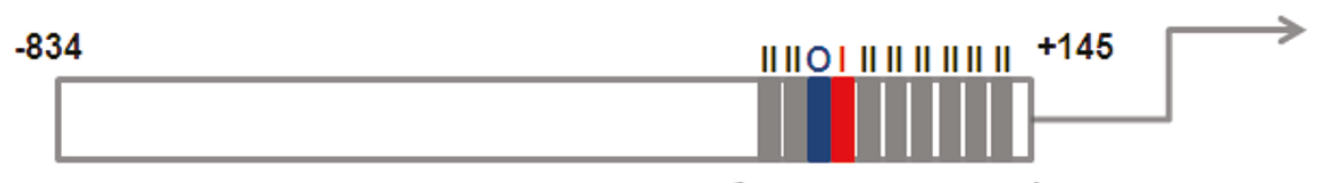

$-258$

$+145$

ccaagccctgttgcgtcggcgggaggggcatgctaatggggttcttgggggacaccgggttgggccccaaatc

gggggccgggccgtgcatgctaatgatattctttgggggcgecgggttggtccccggggacggggecgccccgcg

Oct-1NP16

gtgggcctgcctccctgggacgcgcggccattgggggaatcgtcactgccgccctttggggaggggaaaggcg ICP4/CRE SP1

tggggtataagttagccetggeccgacagtctggtcgcatttgcacctcggcactcggagcgagacgcagcagcca

ggcagactcgggccgcccctctccgcatcaccacagaagccccgcctacgttgcgaccccagggaccctccgt ccgcgaccetccagccgcatacgacccc

B.

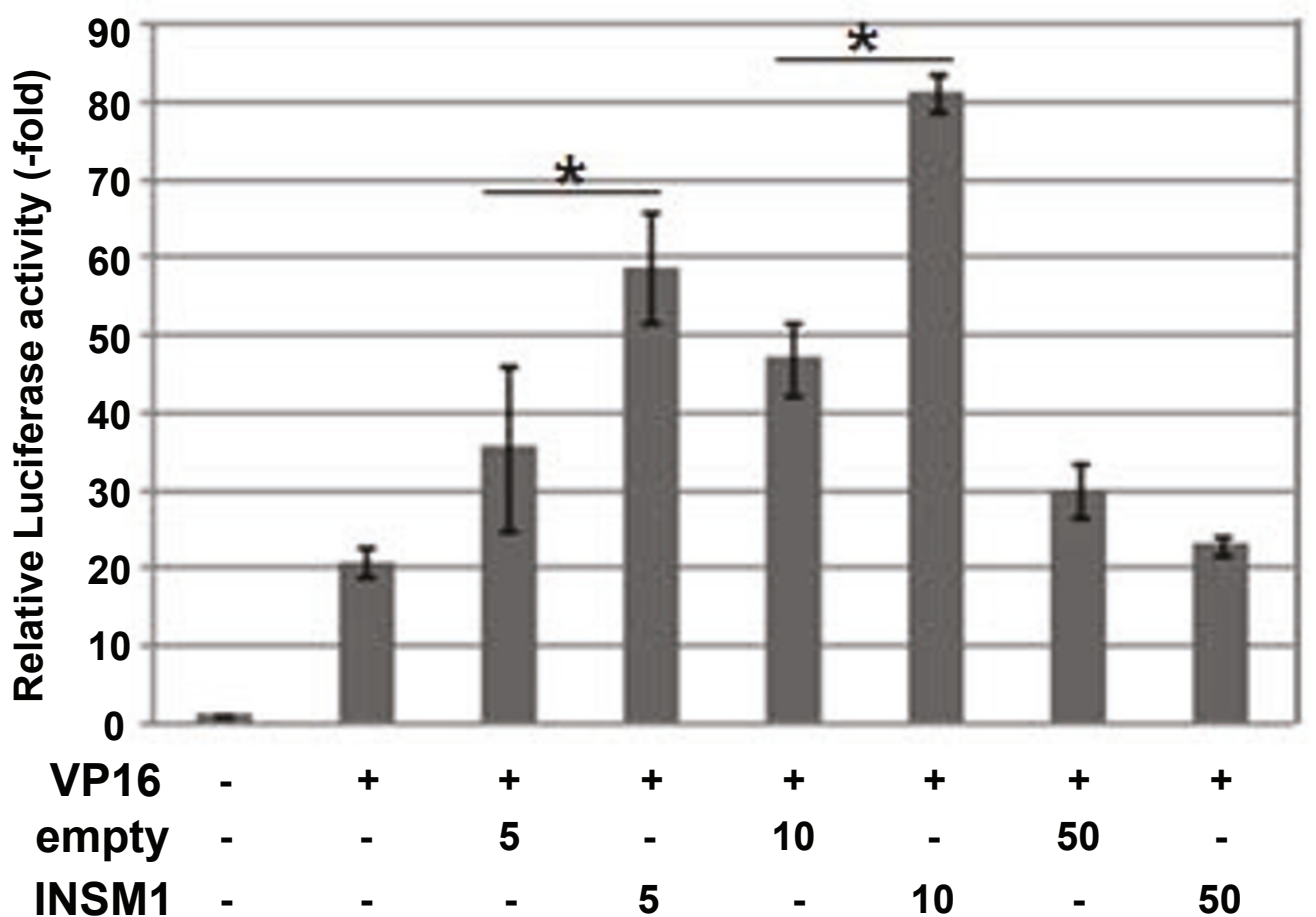

Figure 6 Effect of HSV infection on ICPO promoter-derived luciferase activities. (A) Graphical representation of the nucleotide sequences of the ICPO promoter region from position -834 to +145 . The HSV-1 ICPO promoter has several potential INSM1-binding sites (red, INSM1-binding consensus site, 5'-TCCCCGGGGACG-3'; gray, INSM1-like binding site, 5'-TNNNNGGGGNCN-3'). The binding sites of well-known transcription factors are as follows: blue, Oct-1NP16 binding site, 5'-ATGCTAATGATAT-3'. (B) HEp-2 cells were transfected with plasmid DNAs containing reporter and effector genes. Luciferase activity was measured as described in Methods. The results are shown as means \pm SD, * $P<0.05$ (Student's $t$ test) relative to the empty vector (EF). 


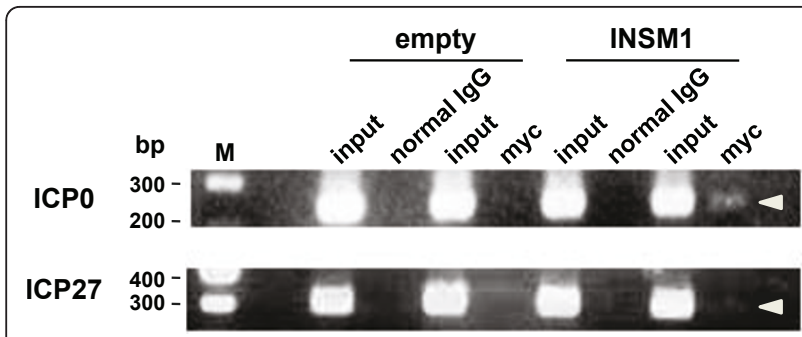

Figure 7 Binding of INSM1 to the ICPO promoter. ChIP assays were performed as described in Methods. INSM1-DNA complexes were incubated with the anti-Myc antibody or normal rabbit lgG. The precipitated and genomic DNAs (input) were subjected to PCR amplification using primers specific for both ICPO and ICP27 promoters. Data represent two independent experiments.

INSM1-specific siRNA inhibits HSV replication The above observations lead us to conclude that INSM1 expression enhances HSV-1 replication. To better support this conclusion, the effect of INSM1 knockdown on the efficiency of viral replication was examined using siRNA technology. INSM1-specific siRNA markedly reduced the level of INSM1 mRNA, but scramble siRNA did not (Figure 8A). Cells were mock-transfected or transfected with either scrambled siRNA or siRNA specific for INSM1, and then infected with $\mathrm{HSV}-1$ at MOI of $0.01 \mathrm{PFU} /$ cell $48 \mathrm{~h}$ after transfection. At $48 \mathrm{~h}$ after infection, culture medium was harvested and assayed for viral infectivity and subjected to Western blot analysis. As shown in Figure 8B and $8 \mathrm{C}$, pretreatment of cells with INSM1-specific siRNA suppressed HSV-1 replication as well as the production of the major capsid protein VP5. These results indicate that INSM1 supports HSV-1 replication in HEp-2 cells.

\section{Discussion}

The transcription factor INSM1 plays an important role in developing neuroendocrine tissues and the nervous system in mammals [9]. The expression pattern of INSM1 is restricted to the fetal tissues and silenced in adult tissues [9]. However, the INSM1 gene is known to be reactivated in neuroendocrine tumors [15,32]. Our present study shows that transcriptional expression of the INSM1 gene was markedly up-regulated by HSV-1 or HSV-2 infection. This marked increase was observed in normal and human tumor cell lines. In addition, we employed an INSM1 promoter-driven luciferase expression vector to confirm that INSM1 promoter activity was markedly elevated by infection with HSV and not with UV-inactivated HSV, strongly suggesting that HSV gene expression is necessary for activating the INSM1 promoter. Since an immediate early gene product, ICP4 is well known to activate the expression of cellular genes, it is a possible candidate for a transactivator of

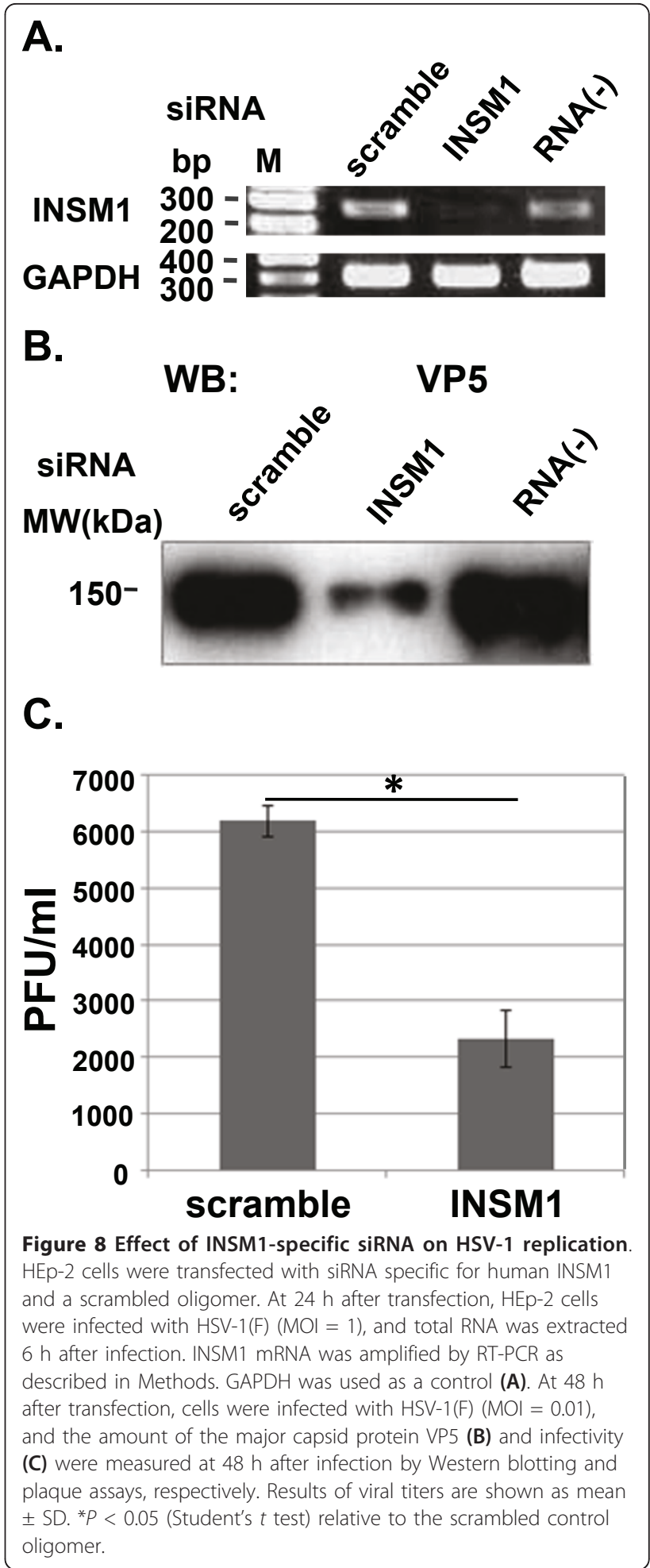

the INSM1 gene. Previous studies have shown that ICP4 forms a tripartite complex with TFIIB and TATA binding protein (TBP) on DNA and interacts with TBP associated factor 250 (TAF250) [33,34]. ICP4 promotes the formation of transcription preinitiation complex by 
enhancing TFIID binding to the promoter [35]. Therefore, it is possible that ICP4 could transactivate INSM1. VP16 could also be involved in the activation of the ISNM1 promoter. However, the exact mechanism by which HSV infection activates the INSM1 promoter remains to be determined.

The INSM1 gene, similar to most HSV genes, lacks introns [25]. The IE protein ICP27 inhibits host cell mRNA splicing, resulting in the accumulation of unspliced transcripts in the nucleus and mediates RNA export of intronless mRNA. Therefore, we expected that the INSM1 gene product could be detected in HSVinfected cells but failed to detect it, probably because of the low specificity and reactivity of the anti-INSM1 antibody used. Currently, whether up-regulation of INSM1 mRNA in HSV-infected cells result in the production of functional INSM1 is unclear.

We constructed the expression vectors of INSM1-FL and its $\mathrm{N}$ - and $\mathrm{C}$-terminal domains fused in the frame with the Myc-tag epitope. Using these expression vectors, we observed that INSM1 expression enhanced ICP0 expression early in infection. Nucleotide sequence analysis showed that the upstream promoter region of ICP0 contained an INSM1-binding consensus sequence and several potential INSM1-binding sequences, suggesting that INSM1 directly exerted its effect on ICP0 expression by binding its promoter region. In fact, our reporter gene assays showed that INSM1 significantly stimulated the ICP0 promoter in the presence of the virion-associated transactivator VP16. However, the addition of increased amounts of the INSM1 expression vector suppressed luciferase expression. When added at high concentrations, VP16 might attract Oct-1 and HCF to vector sites instead of ICP0 promoter. It seems likely that some kind of swamping would be induced in the expression vectors. In this study, we also showed that INSM1 binds the ICP0 promoter but not the ICP27 promoter. Taken together, our results strongly suggest that INSM1 regulates ICP0 expression by binding the ICP0 promoter. However, INSM1 could also indirectly modulate ICP0 expression by inducing expression of cellular factors involved in ICP0 expression.

Based on the amino acid sequences, INSM1 can be functionally divided into $\mathrm{N}$ - and C-terminal regions [9]. The C-terminal region of human INSM1 contains five zinc finger domains that mediate DNA binding activity. The N-terminal region contains a putative NLS and two proline-rich domains that can serve as protein-protein interacting domains. In fact, the proline-rich $\mathrm{N}$-terminal portion of INSM1 has recently been shown to specifically bind cyclin D1, a key cell cycle regulator, and that through this interaction, INSM1 interrupts the interaction between cyclin D1 and cyclin-dependent kinase 4 (CDK4), which subsequently inhibits Rb phosphorylation
[26]. HSV induces Rb hypophosphorylation in infected cells, and it has been suggested that the inhibition of although the precise mechanism remains unclear [36]. We therefore postulate that INSM1 can directly and indirectly modulate transcriptional expression of ICPO.

Subcellular localization of ICP0 was markedly affected by INSM1 overexpression late in infection. During the IE phase of infection, ICP0, a RING finger E3 ubiquitin ligase, is exclusively nuclear and acts as a nuclear regulator of HSV mRNA synthesis [37]. However, ICP0 translocates to the cytoplasm during the early phase [28], and a recent study showed that cytoplasmic ICP0 plays a role in virion maturation and/or egress by dismantling the host cell's microtubules networks [38]. Our observations showed that INSM1 inhibits the translocation of ICP0 to the cytoplasm. Recently, Kalamavoki and Riozman showed that inhibition of CDK4 kinase activity inhibits the translocation of ICP0 from the nucleus to the cytoplasm in infected cells [39]. INSM1 can indirectly inhibit CDK4 function through its interaction with cyclin D1, and therefore, the N-terminal proline-rich domains of INSM1 may be involved in this phenomenon. In the late stage of the replication cycle, INSM1 may inhibit virus replication. However, this effect may be an artifact caused by INSM1 overexpression in transfected cells.

\section{Conclusions}

In summary, our study clearly demonstrates that HSV infection up-regulates the expression of INSM1 which can regulate expression and localization of the IE protein ICP0. Since the INSM-specific siRNA inhibited the growth of HSV-1, we conclude that INSM1 induction plays a positive role in viral replication. It is well known that ICP0 is sufficient to trigger HSV reactivation in latently infected trigeminal ganglion neurons. INSM1 may be involved as a host factor in the reactivation of HSV latency. We are now investigating the roles of INSM1 in the HSV life cycle in a mouse model system.

\section{Methods}

\section{Cells and viruses}

Vero cells derived from a stable African monkey kidney were propagated in Eagle's minimal essential medium (EMEM) containing 10\% calf serum. HEp-2 cells derived from a human laryngeal carcinoma were propagated in Dulbecco's modified Eagle medium (DMEM) containing $10 \%$ fetal calf serum (FCS). HaCaT, a human keratinocyte cell line, was kindly provided by Dr. Norbert E Fusenig (German Cancer Resarch Center, Heidelberg, Germany) [40]. HaCaT cells were propagated in DMEM containing 5\% FCS. SBC-3 cells derived from a human small-cell lung carcinoma were propagated in EMEM containing 10\% FCS (provided by Health Sciences 
Research Resources Bank, Japan). A primary culture of NHEK of neonatal foreskin (NHEK(F)) was obtained from Kurabo (Osaka, Japan) and subcultured in Humedia-KB2 medium (Kurabo) supplemented with bovine pituitary extract $(0.4 \% \mathrm{v} / \mathrm{v})$, human epidermal growth factor $(0.1 \mathrm{ng} / \mathrm{ml})$, insulin $(10 \mu \mathrm{g} / \mathrm{ml})$, hydrocortisone $(0.5 \mu \mathrm{g} / \mathrm{ml})$, gentamycin $(50 \mu \mathrm{g} / \mathrm{ml})$, and amphotericin B $(50 \mathrm{ng} / \mathrm{ml})$ (Complete Humedia-KG2). All viruses were propagated and titered on Vero cells. The WT HSV-1 strain $\mathrm{F}$ and its $\triangle \mathrm{US} 3$ mutant R7041 were kindly provided by B. Roizman, University of Chicago. The properties of the WT HSV-2 strain 186 and its $\Delta$ US3 mutant L1BR1 have been described [41]. Viruses were propagated in Vero cells by infection at a low MOI (0.01 $\mathrm{PFU} / \mathrm{cell})$, and infected cells and growth medium were harvested together when almost all cells showed cytopathic effects. Virus stocks were prepared by one cycle of freezing and thawing followed by centrifugation at $3,000 \mathrm{rpm}$ for $5 \mathrm{~min}$ at $4^{\circ} \mathrm{C}$ to remove cell debris, and then stored at $-80^{\circ} \mathrm{C}$. Virus stock titers were determined on Vero cells by plaque assay. Subconfluent NHEK cells plated in 10-cm dishes were mock-infected or infected with HSV-1 (F, R7041) or HSV-2 (186, L1BR1) (3 PFU/ cell) for $60 \mathrm{~min}$ at $37^{\circ} \mathrm{C}$, followed by the addition of DMEM containing $1 \%$ FCS.

\section{RNA isolation}

At the indicated times after infection, the medium was removed and cells were washed with PBS and then lysed with ISOGEN reagent (Nippon Gene Co., Toyama, Japan). Lysates were stored at $-80^{\circ} \mathrm{C}$. RNA for microarray analysis was isolated with Isogen and purified using the RNeasy MinElute kit (Qiagen, Valencia, CA, USA) according to the manufacturer's instructions. RNA quality was assessed using an Agilent 2100 Bioanalyzer (Agilent Technologies, Palo Alto, CA). Double-stranded cDNA was synthesized using a T7-oligo (dT) primer and the One-cycle cDNA synthesis kit (Affymetrix Inc., Santa Clara, CA) and subsequently purified using a Sample Cleanup Module (Affymetrix).

\section{Microarray data analysis}

Hybridization samples were prepared and processed according to the GeneChip Expression Analysis Technical Manual, 701021 Rev. 5. The Human Genome U133 plus 2.0 chips comprise 54,765 probe sets. Data were analyzed using the GeneChip Operating Software version 1.4 (Affymetrix 690036) according to the GeneChip Expression Analysis Data Analysis Fundamentals. Using DNA MicroArray Viewer (Kurabo, Osaka, Japan), fold changes in expression between each of the infected samples compared with mock-infected controls of the same cell type were calculated ( $\log _{2}$ transformed) and further classified as unchanged, increased (signal log ratio change $P$ value of $<0.005$ ), decreased (signal $\log$ ratio change $P$ value of $>0.995$ ), or marginally increased or decreased. Sequences that showed differential expression in infected cells were grouped according to the GeneOntology terms for biological processes, available on the National Center for Biotechnology Information website (March 2006, NCBI Build 36.1). Sequences not yet annotated by GeneOntology were not analyzed further. Genes that could be placed into more than 1 group according to these annotations were arbitrarily assigned to a single group.

\section{RT-PCR analysis}

INSM1 mRNA levels were determined by RT-PCR. To ensure the absence of genomic DNA contamination, the samples were tested by PCR without RT. First-strand cDNA was prepared from $1 \mu \mathrm{g}$ total RNA using the Promega reverse transcription system (Promega, Madison, Wisconsin, USA, A3500), and cDNA was used as a PCR template for TaKaRa Ex Taq (TAKARA BIO INC, Shiga, Japan, RR001A). The PCR conditions were as follows: $98^{\circ} \mathrm{C}$ for $10 \mathrm{~s}, 58^{\circ} \mathrm{C}$ for $30 \mathrm{~s}$, and $72^{\circ} \mathrm{C}$ for $30 \mathrm{~s}$. The primers used were as follows: human INSM1, (forward) 5'-AACTGTGCCTTCGCTTGGA-3' and (reverse) 5'-ACGAGACAAACGCGTACAGCT-3' (269-bp product); human GAPDH, (forward) 5'-CGGAGTCAACGGATTTGGTCGTAT-3' and (reverse) 5'-AGCCTTC TCCATGGTGGTGAAGAC-3' (307-bp product).

\section{Plasmids and constructs}

Human INSM1 cDNA was amplified from SBC3 cells by PCR using specific primers (forward, 5'- GCCGGATCCAACATGCCCCGCGGCTTCCTGGTGAA -3'; reverse, 5' - CGGAATTCCAGCAGGCCGGGCGCACGGG-3') and KOD FX (TOYOBO, Osaka, Japan, KFX-101). The PCR conditions were as follows: denaturation at $94^{\circ} \mathrm{C}$ for $2 \mathrm{~min}, 35$ cycles of denaturation at $98^{\circ} \mathrm{C}$ for $10 \mathrm{~s}$, and extension at $68^{\circ} \mathrm{C}$ for $1 \mathrm{~min} 30 \mathrm{~s}$. The PCR products were electrophoresed on a $1.5 \%$ agarose gel, and fragments were extracted using a QIAquick Gel Extraction kit (Qiagen). These extracted fragments were amplified by PCR under the abovementioned conditions using specific primers containing BamHI and EcoRI sites. The PCR products were digested with BamHI and EcoRI and cloned into the respective cognate sites of pEF-mycHisB (Invitrogen, Carlsbad, CA, USA). cDNA fragments of INSM1 mutants were amplified from full-length. pEFINSM1-C was constructed using PCR on this template with primers (forward, 5'-CGGGATCCAACATGGAGGGCCCGGTGGAG-3' and reverse, 5' $^{\prime}$ - CGGAAT TCCAGCAGGCCGGGCGCACGGG-3') followed by substitution of a BamHI- and EcoRI-restricted amplified fragment. pEF-INSM1-N was constructed using PCR with a reverse primer $5^{\prime}$-CGGAATTCACCGGGCCC 
TCCTTGAT-3' to delete INSM1-C. The VP16 expression vector pCDNA-HSV-1 UL48 has been described [42]. The complete coding sequences of all constructs were verified by sequencing.

\section{Transfection and infection}

Cells were plated on 35-mm dishes and incubated for 24 $\mathrm{h}$ before transfection or infection. Cells were transfected with $1 \mu \mathrm{g}$ of each plasmid DNA using FugeneHD (Roche Applied Science, Indianapolis, IN, USA, 04709705001) according to the manufacturer's recommendations. In some experiments, transfected cells were also infected with HSV-1(F) 20-24 h after transfection. Infections were performed by exposing cells to a minimal volume of virus diluted at MOI of $3 \mathrm{PFU} /$ cell in EMEM without FCS. After $1 \mathrm{~h}$ of adsorption, the virus inoculum was replaced with DMEM containing 1\% FCS and cells were incubated for the indicated time periods.

\section{Immunofluorescence confocal microscopy}

Indirect immunofluorescence confocal microscopy was performed as previously described with modifications [42]. In brief, cells grown on cover slips were fixed in $4 \%$ paraformaldehyde in PBS for $20 \mathrm{~min}$ and permeabilized with $0.5 \%$ Triton X-100 for 5 min at room temperature. Coverslips were incubated for $1 \mathrm{~h}$ at $37^{\circ} \mathrm{C}$ sequentially with $20 \%$ normal goat serum (DAKO, Glostrup, Denmark) and primary and secondary antibodies (30 min for each). The following primary antibodies were used: polyclonal anti-Myc (1:100 dilution; Santa Cruz Biotechnology, Inc., sc-40) and anti-INSM1 (1:100 dilution; Abcam, ab30940) antibodies; monoclonal antiICP0 (1:100 dilution; Virusys, H1A027-100) and antiICP8 (1:50 dilution; Abcam, ab20194) antibodies. FITCor TRITC-conjugated goat anti-rabbit and anti-mouse antibodies were used as secondary antibodies. In some experiments, coverslips were additionally incubated with DRAQ5 $^{\mathrm{TM}}$ (1:4,000, Biostatus, Leicestershire, UK) for 30 $\mathrm{min}$ at room temperature to stain nuclear DNA together with secondary antibody staining. For double staining with two different mouse monoclonal antibodies, mouse anti-Myc and anti-ICP0 or anti-ICP8 antibodies were directly conjugated with AlexaFluor 488 and 555, respectively, using the Zenon Mouse IgG1 labeling kit (Molecular Probes, Eugene, OR, Z25002 and Z25005) according to the manufacturer's protocol, and cells were incubated sequentially with each antibody. Confocal images were captured using the Zeiss LSM510 system (Carl Zeiss, Jena, Germany). Images were acquired and processed using Adobe Photoshop Elements 7.

\section{Luciferase Reporter Assay}

To generate luciferase reporter plasmids of the human INSM1 promoter, PCR fragments $(-441$ to $+26 \mathrm{bp})$ from the HEp-2 genome were inserted into the KpnI and $\mathrm{XhoI}$ sites of the pGL3 basic luciferase expression vector (Promega, \#E1751). To generate luciferase reporter plasmids of the HSV-1 ICP0 promoter, PCR fragments $(-834$ to $+145 \mathrm{bp})$ from the HSV-1(F)infected HEp-2 genome were inserted into the KpnI and XhoI sites of the pGL3 basic luciferase expression vector. Using FugeneHD, HEp-2 or HaCaT cells were transfected with luciferase reporter plasmids and INSM1 expression plasmids according to the manufacturer's instructions. The cells were plated in 48-well plates and transfected with expression vectors and a reporter gene. HEp-2 or $\mathrm{HaCaT}$ cells in 48 -well plates were transfected into cells at $30-40 \%$ confluence. Triplicate wells received $100 \mathrm{ng}$ of reporter plasmid and 5-50 ng of expression vector DNAs, and cells were harvested for luciferase assays after $24 \mathrm{~h}$. HEp- 2 or $\mathrm{HaCaT}$ cells were cultured in 48-well microplates and transfected with $100 \mathrm{ng}$ of hINSM1-Luc or ICP0-Luc reporter plasmids and the desired expression plasmids (5-50 ng of each expression plasmid). The total amount of plasmid DNA was kept constant by balancing with the empty vector. Transfection mixtures were added dropwise into cell culture medium and incubated at $37^{\circ} \mathrm{C}$ for $48 \mathrm{~h}$. Transfected cells were harvested in PBS and lysed with $50-70 \mu \mathrm{l}$ of $1 \times$ passive lysis buffer (Promega, E1941). Cell lysates were clarified by centrifugation and assayed for luciferase activity using the luciferase assay system (Promega, E1483). Luciferase activity was normalized by protein concentration of each sample, which was determined by the Bio-Rad Protein assay kit (BIO-RAD, \#500-0006).

\section{ChIP assay}

Forty-eight hours after transfection, transfectants were infected with HSV-1(F) at MOI of $3 \mathrm{PFU} /$ cell $7 \mathrm{~h}$ postinfection. The cells were fixed by adding formaldehyde to the medium (1\% final concentration) for $15 \mathrm{~min}$ at room temperature. The cross-linking reaction was terminated by adding glycine to a final concentration of $0.125 \mathrm{M}$. The fixed cells were washed twice in ice-cold PBS and solubilized in SDS lysis buffer (1\% SDS, 10 $\mathrm{mM}$ EDTA, $50 \mathrm{mM}$ Tris- $\mathrm{HCl}, \mathrm{pH}$ 8.0) containing protease inhibitor cocktail (Sigma-Aldrich), and $10 \mu \mathrm{M}$ PMSF for $20 \mathrm{~min}$ on ice. The chromatin complexes were sheared by sonication to an average fragment size of 200-500 bp. Sonication was performed with Bioruptor (Cosmo bio co., Ltd., Tokyo, Japan), using $100 \mu \mathrm{l}$ in 1.5 $\mathrm{ml}$ tube. One time of sonication was done with $30 \mathrm{~s}$ on and $30 \mathrm{~s}$ off with high power. Ten times of sonication were performed with $10 \mathrm{~min}$. ChIP assays were performed using the OneDay ChIP assay kit (Diagenode, Nippon Gene 313-86401) according to the manufacturer's protocol. Cells were lysed in SDS lysis buffer (1\% 
SDS, $10 \mathrm{mM}$ EDTA, $50 \mathrm{mM}$ Tris- $\mathrm{HCl}, \mathrm{pH}$ 8.0) containing protease inhibitor cocktail (Sigma-Aldrich) and 10 $\mu \mathrm{M}$ PMSF and then sonicated. Chromatin solution was subjected to immunoprecipitation using a OneDay ChIP kit (Diagenode, Sparta, NJ) according to the manufacturer's instructions. The following antibodies were used: anti-Myc (Santa Cruz Biotechnology, Inc., sc-789) and negative control rabbit IgG (contained in the OneDay ChIP assay kit). The HSV-1 ICP0 promoter was amplified by PCR using the following primers: (forward) $5^{\prime}-$ AAGCCCCTGTTGCGTCGGCG-3' and (reverse) 5'TTATCCCCACGCCTTTCCC-3' (234 bp). As a negative control, the HSV-1 ICP27 promoter was amplified using the following primers: 5'-GGGGTACCCCCAACGACCCCGCCCATGGG-3' and 5'-GGCTCGAGG GGGTGTCGGATATCGCCTCT-3' (396 bp).

\section{Gene Silencing}

To knock down INSM1 expression, HEp-2 cells were transfected with an INSM1-specific siRNA (5'-UCCGCAAGCUGCACUUCGATT-3') or a scrambled (5'GCAUUCCAUCGCGCGGUCACATT-3') $(20 \mu \mathrm{M}$; Nippon EGT Co., Ltd.) ribooligonucleotide using $\mathrm{X}$-tremeGENE siRNA transfection reagent (Roche, \#04476093001). At $24 \mathrm{~h}$ after siRNA transfection, HEp-2 cells were infected with HSV-1(F) at MOI of 1, and total RNA was extracted $6 \mathrm{~h}$ after infection and analyzed by RT-PCR. At 24 h posttransfection, HEp2 cells were infected with HSV-1 at MOI of $0.01 \mathrm{PFU} / \mathrm{cell}$ at $24 \mathrm{~h}$. Total protein lysate or culture medium were collected and analyzed by western blotting or virus titration, respectively.

\section{Statistics}

Data were analyzed by Student's $t$ test. $P<0.05$ was considered significant.

\section{Acknowledgements \\ We thank Bernard Roizman for HSV-1 (F, R7041); and Norbert E Fusening for HaCaT cells. We also thank Yoko Ushijima, Akane Ohta, Shinichi Esaki, Yoshifumi Muto, Seiko Iwata, and Zhuan Li for technical suggestions and discussions, and Hiromi Noma and Tomoko Kunogi for technical assistance. This study was supported by a research grant (number 22390088) from the Ministry of Education, Culture, Sports, Science and Technology of Japan.}

\section{Authors' contributions}

MK and $Y N$ designed the research, MK, FG, and $C L$ performed the experimental work, MK conducted data analysis and drafted the manuscript, and FG, HK, and YN participated in data analysis and review of the manuscript. All authors read and approved the final manuscript.

\section{Competing interests}

The authors declare that they have no competing interests.

Received: 10 February 2011 Accepted: 25 May 2011

Published: 25 May 2011
References

1. Nishiyama Y: Herpes simplex virus gene products: the accessories reflect her lifestyle well. Rev Med Virol 2004, 14:33-46.

2. Godowski PJ, Knipe DM: Transcriptional control of herpesvirus gene expression: gene functions required for positive and negative regulation. Proc Natl Acad Sci USA 1986, 83:256-260.

3. Weir JP: Regulation of herpes simplex virus gene expression. Gene 2001, 271:117-130.

4. Honess RW, Roizman B: Regulation of herpesvirus macromolecular synthesis: sequential transition of polypeptide synthesis requires functional viral polypeptides. Proc Natl Acad Sci USA 1975, 72:1276-1280.

5. Knipe DM, Cliffe A: Chromatin control of herpes simplex virus lytic and latent infection. Nat Rev Microbiol 2008, 6:211-221.

6. Roizman B, Knipe DM, Whitley Peter RJ: Herpes Simplex Viruses. In Fields virology.. 5 edition. Edited by: Knipe DM. Philadelphia: Lippincott Williams 2007:2502-2601.

7. Sandri-Goldin RM: The many roles of the regulatory protein ICP27 during herpes simplex virus infection. Front Biosci 2008, 13:5241-5256.

8. Kamakura M, Nawa A, Ushijima Y, Goshima F, Kawaguchi Y, Kikkawa F, Nishiyama $Y$ : Microarray analysis of transcriptional responses to infection by herpes simplex virus types 1 and 2 and their US3-deficient mutants. Microbes Infect 2008, 10:405-413.

9. Lan MS, Breslin MB: Structure, expression, and biological function of INSM1 transcription factor in neuroendocrine differentiation. FASEB J 2009, 23:2024-2033.

10. Xie J, Cai T, Zhang H, Lan MS, Notkins AL: The zinc-finger transcription factor INSM1 is expressed during embryo development and interacts with the Cbl-associated protein. Genomics 2002, 80:54-61.

11. Zhu M, Breslin MB, Lan MS: Expression of a novel zinc-finger CDNA, IA-1, is associated with rat AR42J cells differentiation into insulin-positive cells. Pancreas 2002, 24:139-145.

12. Breslin MB, Zhu M, Lan MS: NeuroD1/E47 regulates the E-box element of a novel zinc finger transcription factor, IA-1, in developing nervous system. J Biol Chem 2003, 278:38991-38997.

13. Gierl MS, Karoulias N, Wende H, Strehle M, Birchmeier C: The zinc-finger factor Insm1 (IA-1) is essential for the development of pancreatic beta cells and intestinal endocrine cells. Genes Dev 2006, 20:2465-2478.

14. Mellitzer G, Bonne S, Luco RF, Van De Casteele M, Lenne-Samuel N, Collombat P, Mansouri A, Lee J, Lan M, Pipeleers D, et al: IA1 is NGN3dependent and essential for differentiation of the endocrine pancreas. EMBO J 2006, 25:1344-1352

15. Lan MS, Russell EK, Lu J, Johnson BE, Notkins AL: IA-1, a new marker for neuroendocrine differentiation in human lung cancer cell lines. Cancer Res 1993, 53:4169-4171.

16. Pedersen N, Pedersen MW, Lan MS, Breslin MB, Poulsen HS: The insulinoma-associated 1: a novel promoter for targeted cancer gene therapy for small-cell lung cancer. Cancer Gene Ther 2006, 13:375-384.

17. Wang HW, Breslin MB, Chen C, Akerstrom V, Zhong Q, Lan MS: INSM1 promoter-driven adenoviral herpes simplex virus thymidine kinase cancer gene therapy for the treatment of primitive neuroectodermal tumors. Hum Gene Ther 2009, 20:1308-1318.

18. Wildner H, Gierl MS, Strehle M, Pla P, Birchmeier C: Insm1 (IA-1) is a crucial component of the transcriptional network that controls differentiation of the sympatho-adrenal lineage. Development 2008, 135:473-481.

19. Farkas LM, Haffner C, Giger T, Khaitovich P, Nowick K, Birchmeier C, Paabo S, Huttner WB: Insulinoma-associated 1 has a panneurogenic role and promotes the generation and expansion of basal progenitors in the developing mouse neocortex. Neuron 2008, 60:40-55.

20. Daikoku T, Yamashita Y, Tsurumi T, Maeno K, Nishiyama Y: Purification and biochemical characterization of the protein kinase encoded by the US3 gene of herpes simplex virus type 2. Virology 1993, 197:685-694.

21. Frame MC, Purves FC, McGeoch DJ, Marsden HS, Leader DP: Identification of the herpes simplex virus protein kinase as the product of viral gene US3. J Gen Virol 1987, 68(Pt 10):2699-2704.

22. Purves FC, Longnecker RM, Leader DP, Roizman B: Herpes simplex virus protein kinase is encoded by open reading frame US3 which is not essential for virus growth in cell culture. J Virol 1987, 61:2896-2901.

23. Kurachi R, Daikoku T, Tsurumi T, Maeno K, Nishiyama Y, Kurata T: The pathogenicity of a US3 protein kinase-deficient mutant of herpes simplex virus type 2 in mice. Arch Virol 1993, 133:259-273. 
24. Reynolds $A E$, Ryckman BJ, Baines JD, Zhou Y, Liang L, Roller RJ: U(L)31 and $U(L) 34$ proteins of herpes simplex virus type 1 form a complex that accumulates at the nuclear rim and is required for envelopment of nucleocapsids. J Virol 2001, 75:8803-8817.

25. Lan MS, Li Q, Lu J, Modi WS, Notkins AL: Genomic organization, 5'upstream sequence, and chromosomal localization of an insulinomaassociated intronless gene, IA-1. J Biol Chem 1994, 269:14170-14174.

26. Zhang T, Liu WD, Saunee NA, Breslin MB, Lan MS: Zinc finger transcription factor INSM1 interrupts cyclin D1 and CDK4 binding and induces cell cycle arrest. J Biol Chem 2009, 284:5574-5581.

27. Breslin $M B$, Zhu M, Notkins $A L$, Lan MS: Neuroendocrine differentiation factor, IA-1, is a transcriptional repressor and contains a specific DNAbinding domain: identification of consensus IA-1 binding sequence. Nucleic Acids Res 2002, 30:1038-1045.

28. Lopez P, Van Sant C, Roizman B: Requirements for the nuclearcytoplasmic translocation of infected-cell protein 0 of herpes simplex virus 1. J Virol 2001, 75:3832-3840.

29. Douville P, Hagmann M, Georgiev O, Schaffner W: Positive and negative regulation at the herpes simplex virus ICP4 and ICPO TAATGARAT motifs. Virology 1995, 207:107-116.

30. Davido DJ, Leib DA: Analysis of the basal and inducible activities of the ICPO promoter of herpes simplex virus type 1. J Gen Virol 1998, 79(Pt 9):2093-2098.

31. Kwun HJ, Jang KL: Transcriptional regulation of herpes simplex virus type 1 ICP0 promoter by virion protein 16. Mol Cell Biol Res Commun 2000, 3:15-19.

32. Li Q, Notkins AL, Lan MS: Molecular characterization of the promoter region of a neuroendocrine tumor marker, IA-1. Biochem Biophys Res Commun 1997, 236:776-781.

33. Carrozza MJ, DeLuca NA: Interaction of the viral activator protein ICP4 with TFIID through TAF250. Mol Cell Biol 1996, 16:3085-3093.

34. Smith CA, Bates P, Rivera-Gonzalez R, Gu B, DeLuca NA: ICP4, the major transcriptional regulatory protein of herpes simplex virus type 1 , forms a tripartite complex with TATA-binding protein and TFIIB. J Virol 1993, 67:4676-4687.

35. Grondin B, DeLuca N: Herpes simplex virus type 1 ICP4 promotes transcription preinitiation complex formation by enhancing the binding of TFIID to DNA. J Virol 2000, 74:11504-11510.

36. Hume AJ, Kalejta RF: Regulation of the retinoblastoma proteins by the human herpesviruses. Cell Div 2009, 4(1).

37. Hagglund R, Roizman B: Role of ICPO in the strategy of conquest of the host cell by herpes simplex virus 1. J Virol 2004, 78:2169-2178.

38. Liu M, Schmidt EE, Halford WP: ICPO dismantles microtubule networks in herpes simplex virus-infected cells. PLoS One 2010, 5:e10975.

39. Kalamvoki M, Roizman B: Interwoven roles of cyclin D3 and cdk4 recruited by ICPO and ICP4 in the expression of herpes simplex virus genes. J Virol 2010, 84:9709-9717.

40. Boukamp P, Petrussevska RT, Breitkreutz D, Hornung J, Markham A, Fusenig NE: Normal keratinization in a spontaneously immortalized aneuploid human keratinocyte cell line. J Cell Biol 1988, 106:761-771

41. Nishiyama Y, Yamada Y, Kurachi R, Daikoku T: Construction of a US3 lacZ insertion mutant of herpes simplex virus type 2 and characterization of its phenotype in vitro and in vivo. Virology 1992, 190:256-268.

42. Yamauchi Y, Kiriyama K, Kubota N, Kimura H, Usukura J, Nishiyama Y: The UL14 tegument protein of herpes simplex virus type 1 is required for efficient nuclear transport of the alpha transinducing factor VP16 and viral capsids. J Virol 2008, 82:1094-1106.

doi:10.1186/1743-422X-8-257

Cite this article as: Kamakura et al:: Herpes simplex virus induces the marked up-regulation of the zinc finger transcriptional factor INSM1 which modulates the expression and localization of the immediate early protein ICPO. Virology Journal 2011 8:257.

\section{Submit your next manuscript to BioMed Central and take full advantage of:}

- Convenient online submission

- Thorough peer review

- No space constraints or color figure charges

- Immediate publication on acceptance

- Inclusion in PubMed, CAS, Scopus and Google Scholar

- Research which is freely available for redistribution

Submit your manuscript at www.biomedcentral.com/submit
Biomed Central 